\title{
ИССЛЕДОВАНИЕ КОЛЛОИДНЫХ КВАНТОВЫХ ТОЧЕК АGINS $/ 2$ ZNS В КАЧЕСТВЕ ФЛУОРЕСЦЕНТНЫХ МЕТОК ДЛЯ ТЕРАНОСТИКИ: ФИЗИЧЕСКИЕ СВОЙСТВА, БИОРАСПРЕДЕЛЕНИЕ И БИОСОВМЕСТИМОСТЬ
}

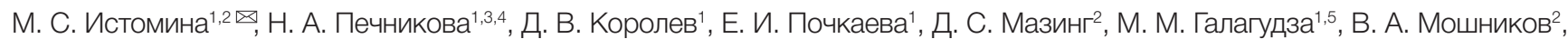
Е. В. Шляхто ${ }^{1}$

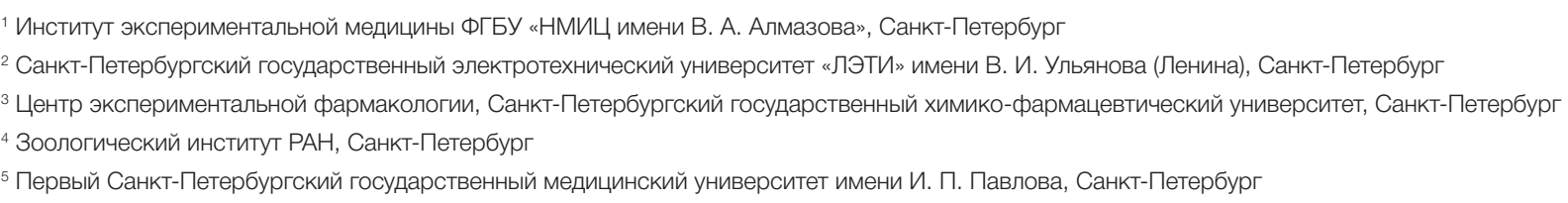

В последние годы отмечается повышение интереса к использованию коллоидных квантовых точек (КT) в биологии и медицине. В частности, КТ могут представлять собой перспективные наноразмерные объекты для тераностики, при которой за счет специфического накопления нагруженных лекарственным соединением КТ в патологическом очаге происходят одновременно его визуализация и таргетное терапевтическое воздействие. Одним из ограничений использования КТ в медицине является их потенциальная токсичность, особенно если материал нанокристалла содержит такие элементы, как кадмий и свинец. В связи с этим перспективной представляется разработка меток

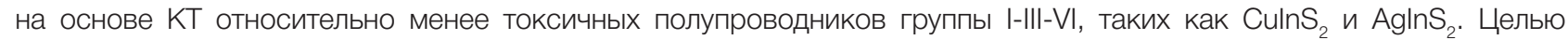
работы было исследование биораспределения и биосовместимости KT на основе соединения AglnS 2 в оболочке ZnS. Для этого проводили синтез КТ инжекционным методом, изучали размеры получаемых КT, их спектры поглощения и фотолюминисценции. Методом флуоресцентного имиджинга исследовали in vivo биораспределение КT. Биосовместимость образцов определяли in vivo по динамике изменения массы тела животных и при помощи гематологических исследований. При изучении биораспределения было выявлено накопление КТ в таких органах, как печень, легкие, сердце и почки. Показано, что КТ в диапазоне доз от $2 \cdot 10^{-7}$ до 4 • 10-6 моль/л при внутривенном введении крысам не оказывают значимого влияния на динамику массы тела и основные гематологические показатели на протяжении 30 дней. Таким образом, КТ на основе соединения AglnS 2 в оболочке ZnS могут быть использованы для визуализации тканей и органов при различных патологических процессах, а возможность иммобилизации на их поверхности лекарственных средств позволит рекомендовать их к применению для тераностики.

Ключевые слова: коллоидные квантовые точки, AglnS 2 /ZnS, тераностика, биораспределение, биосовместимость

$\checkmark$ Для корреспонденции: Мария Сергеевна Истомина

пр. Пархоменко, Д. 15 «Б», г. Санкт-Петербург, 194156; istomina_ms@almazovcentre.ru

Статья получена: 28.07.2018 Статья принята к печати: 23.08.2018

DOI: $10.24075 /$ vrgmu.2018.073

\section{ZAIS-BASED COLLOIDAL QDS AS FLUORESCENT LABELS FOR THERANOSTICS: PHYSICAL PROPERTIES, BIODISTRIBUTION AND BIOCOMPATIBILITY}

\author{
Istomina MS ${ }^{1,2}$, Pechnikova NA ${ }^{1,3,4}$, Korolev DV¹, Pochkayeva El' ${ }^{1}$, Mazing DS², Galagudza MM11,5, Moshnikov VA², Shlyakhto EV ${ }^{1}$ \\ ' Institute of Experimental Medicine, Almazov National Medical Research Centre, St. Petersburg \\ 2 Department of Micro- and Nanoelectronics, St. Petersburg State Electrotechnical University "LETI", St. Petersburg \\ ${ }^{3}$ Center of Experimental Pharmacology, St. Petersburg State Chemical Pharmaceutical Academy, St. Petersburg \\ ${ }^{4}$ Laboratory of Parasitic Arthropods, Zoological Institute of Russian Academy of Sciences, St. Petersburg \\ ${ }^{5}$ Department of Pathophysiology, Pavlov First St. Petersburg State Medical University, St. Petersburg
}

\begin{abstract}
In recent years there has been an increase in interest in the use of colloidal quantum dots (QDs) in biology and medicine. In particular, QDs can be a perspective nanoscale object for theranostics, in which due to the specific accumulation of drugloaded QDs in the pathological focus, its simultaneous visualization and targeted therapeutic influence occur. One of the serious limitations of the use of QDs in medicine is their potential toxicity, especially when the nanocrystal material contains elements such as cadmium or plumbum. Therefore, it is promising to develop labels based on QDs of relatively less toxic semiconductors of group I-III-VI, such as $\mathrm{CulnS}_{2}$ and $\mathrm{AgInS}_{2}$. In this study, biodistribution and biocompatibility of QDs based on the AglnS 2 compound with a ZnS shell (ZAIS) are considered. In the study of biodistribution, the accumulation of QDs in organs such as liver, lungs, heart and kidneys was revealed. It was shown that QDs in the dose range from $2 \cdot 10^{-7}$ to $4 \cdot 10^{-6} \mathrm{M} / \mathrm{L}$ at intravenous administration in rats does not have a significant effect on body mass dynamics and basic hematological parameters for 30 days. Thus, ZAIS QDs can be used to visualize tissues and organs in various pathological processes, and immobilization of the drugs on their surface will allow to approach their application for theranostics.
\end{abstract}

Keywords: colloidal quantum dots, QDs, ZnS-AgInS, ZAIS, theranostics, biodistribution, biocompatibility

$\triangle$ Correspondence should be addressed: Maria S. Istomina

Parkhomenko 15 B, St. Petersburg, 194156; istominams1993@mail.ru

Received: 28.07.2018 Accepted: 23.08.2018

DOI: $10.24075 /$ brsmu.2018.073 
В последнее время активно развивается новый подход к разработке фармацевтических композиций, заключающийся в попытке одновременно решить терапевтические и диагностические задачи [1]. Для этого в качестве диагностических маркеров можно использовать различные флуорофоры [2]. В настоящее время лишь два флуорофора разрешены для клинического применения: индоцианин зеленый и различные комбинации фллуоресцеина [3]. При этом фрлуоресцентные красители имеют существенный недостаток - они выгорают со временем. Материалом, лишенным такого недостатка, являются коллоидные квантовые точки (КТ) [4]. При этом многие КТ обладают токсическими свойствами [5]: кристаллические ядра материалов токсичны при использовании в биомедицине. Нередко в структурах типа «ядро/оболочка» ядром является соединение с тяжелым металлом, а оболочка не полностью покрывает ядро или может быть разрушена, что приводит к высвобождению ионов тяжелых металлов в организм. Было высказано предположение, что токсичность КТ может быть также связана с физико-химическими свойствами оболочек, природой поверхностных «лигандов» (обеспечивающих коллоидную стабильность), наличием других модификаций поверхности и взаимодействием с различными молекулами (например, белками), присутствующими в биологических средах [6-11]. Поэтому важной практической задачей является разработка нетоксичных КТ и изучение их биосовместимости. Результаты исследований, проведенных в последние годы, показывают, что модификация поверхности КТ либо использование КТ определенного состава сопровождаются значительным повышением биосовместимости данных объектов. Так, КТ на основе CdSe/ZnS, конъюгированные с трипептидом аргинин глицин - аспарагиновая кислота (RGD), при системном введении мышам не показали токсических свойств, подтверждаемых гистологическим исследованием, а анализ образцов тканей при помощи масс-спектрометрии не выявил $\mathrm{Cd}^{2+}$ [12]. В другой работе оболочку из биосовместимых сополимеров на основе 2-(2-метоксиэтокси)этилметакрилата и олиго(этиленгликоль)метакрилата выращивали на поверхности квантовых точек ZnO путем поверхностной инициированной радикальной полимеризации [13]. При оценке цитотоксичности по отношению к клеткам НТ29 рака толстой кишки человека было показано, что КТ с полимерным покрытием практически не проявляли токсичности при концентрациях до 12,5 мкг/мл, тогда как при загрузке доксорубицином наблюдались высокая цитотоксичность и снижение жизнеспособности раковых клеток НТ29. Получены и детально охарактеризованы нанокомпозиты, содержащие КТ селенида серебра со средним размером 11,4-12,7 нм, люминесцирующие в области прозрачности биологических тканей (705 нм) [14]. Отсутствия токсических свойств материалов достигали использованием стабилизирующего потенциала природного полисахарида галактоманнана, а также простым экологичным способом генерирования высокореакционноспособных селенид-анионов, выступающих в качестве селенирующего агента. Нетоксичны также углеродные квантовые точки и их сочетания с различными наночастицами, например, на основе железа [15].

Особый интерес представляют КТ, не содержащие потенциально токсичных элементов в своем составе. К таким КТ относятся, в частности, КТ на основе соединения $\mathrm{AglnS}_{2}$ в оболочке ZnS. Целью настоящей работы было изучить физические свойства, биораспределение и биосовместимость КТ на основе $\mathrm{AglnS}_{2} / \mathrm{ZnS}$

\section{МАТЕРИАЛЫ И МЕТОДЫ}

\section{Синтез коллоидных КТ}

Химический синтез коллоидных КТ AglnS $_{2} / \mathrm{ZnS}$ осуществляли инжекционным методом в водной среде. Для достижения баланса реакционной способности катионов индия и серебра в синтезе применяли такие лиганды, как L-глутатион и цитрат натрия. Прекурсоры нитрата серебра - $\mathrm{AgNO}_{3}$ (0,005 ммоль) и нитрата индия $\ln \left(\mathrm{NO}_{3}\right)_{3} \cdot 4,5 \mathrm{H}_{2} \mathrm{O}$ (0,02 ммоль) помещали и растворяли в 5 мл дистиллированной воды в колбе объемом 10 мл. Последовательно в данный раствор добавляли 0,01 ммоль L-глутатиона и 0,08 ммоль цитрата натрия (200 мкл водного раствора). Анионный прекурсорный раствор представлял собой 0,04 ммоль $\mathrm{Na}_{2} \mathrm{~S} \cdot 9 \mathrm{H}_{2} \mathrm{O}$ в 500 мкл дистиллированной воды. В исходный раствор инжектировали прекурсорный раствор серы при комнатной температуре, затем с помощью колбонагревателя производили нагрев до $95^{\circ} \mathrm{C}$ в течение 40 мин. Для создания оболочки, состоящей из сульфида цинка, в 200 мкл дистиллированной воды растворяли 0,02 ммоль нитрата цинка $\left(\mathrm{Zn}\left(\mathrm{NO}_{3}\right)_{2} \cdot 6 \mathrm{H}_{2} \mathrm{O}\right)$ и 0,02 ммоль сульфида натрия $\left(\mathrm{Na}_{2} \mathrm{~S} \cdot 9 \mathrm{H}_{2} \mathrm{O}\right)$. После охлаждения исходного раствора ядер нанокристаллов до комнатной температуры в него вводили одновременно прекурсорный раствор нитрата цинка и сульфида натрия (покапельно), затем нагревали до $95^{\circ} \mathrm{C}$ в течение 40 мин. Для выделения частиц из исходного раствора добавляли изопропиловый спирт с последующим центрифугированием.

\section{Оценка физических свойств КТ}

Оценку размеров КТ осуществляли методом динамического рассеяния света с помощью лазерного анализатора размера частиц SZ100 (Horiba Jobin Yvon, Kyoto; Japan) c диапазоном измерения диаметров наночастиц 0,3-8 мкм. Оптические спектры (поглощения) образцов измеряли с использованием спектрофотометра PE-5400UV (ECROSKHIM

Таблица. Группы животных и концентрации вводимых веществ для исследования биосовместимости КТ

\begin{tabular}{|c|c|c|c|c|c|}
\hline Обозначение группы & $\begin{array}{c}\text { Вводимое } \\
\text { вещество }\end{array}$ & $\begin{array}{c}\text { Концентрация вводимого } \\
\text { вещества, моль/л }\end{array}$ & $\begin{array}{c}\text { Доза действующего } \\
\text { вещества, мл }\end{array}$ & $\begin{array}{c}\text { Время проведения } \\
\text { эксперимента, дни }\end{array}$ & $\begin{array}{c}\text { Количествово животных } \\
\text { в группе }\end{array}$ \\
\hline $\mathrm{KT}-\mathrm{L}(15)$ & $\mathrm{KT}$ & $4 \cdot 10^{-6}$ & 1 & 15 & 5 \\
\hline $\mathrm{KT}-\mathrm{M}(15)$ & $\mathrm{KT}$ & $2 \cdot 10^{-6}$ & 1 & 15 & 5 \\
\hline $\mathrm{KT}-\mathrm{S}(15)$ & $\mathrm{KT}$ & $2 \cdot 10^{-7}$ & 1 & 15 & 5 \\
\hline $\mathrm{Koнтроль}$ & $\mathrm{NaCl}$ & - & 1 & 30 & 5 \\
\hline $\mathrm{KT}-\mathrm{L}(30)$ & $\mathrm{KT}$ & $4 \cdot 10^{-6}$ & 1 & 30 & 5 \\
\hline $\mathrm{KT}-\mathrm{M}(30)$ & $\mathrm{KT}$ & $2 \cdot 10^{-6}$ & 1 & 30 & 5 \\
\hline $\mathrm{KT}-\mathrm{S}(30)$ & $\mathrm{KT}$ & $2 \cdot 10^{-7}$ & 1 & 30 & 5 \\
\hline
\end{tabular}


Co., Ltd; Russia), a спектры фотолюминесценции получали с использованием специально разработанного спектрофлуориметра на основе монохроматора МДР-206 (Lomo Fotonika; Russia).

\section{Оценка биораспределения КТ}

Флуоресцентный имиджинг образцов органов животных, полученных через 1 и 24 ч после внутривенного введения KT, проводили на приборе IVIS Lumina LT Series III (Perkin Elmer; США). Для квантовых точек AglnS $2 / Z n S$ после предварительного исследования спектров поглощения и фотолюминесценции подбирали оптимальные фильтры на фллуоресцентном имиджере. Длина волны возбуждения данных КТ составила $535 \pm 20$ нм, эмиссии - $655 \pm 20$ нм.

\section{Исследование биосовместимости КТ}

Оценку биосовместимости проводили на крысах-самцах стока Wistar SPF-категории (питомник лабораторных животных «Пущино»; Россия). Масса тела животных составляла $235 \pm 23$ г. Исследуемые КТ вводили в течение 3 мин в латеральную хвостовую вену. Формирование групп животных и их краткая характеристика представлены в таблице. Для идентификации квантовых точек и их концентраций вводили следующие обозначения: концентрация КТ 3,7 • 10-9 моль/кг — L (large), 1,85 • 10-9 моль/к $\mathrm{M}$ (medium), 1,85 • 10-10 моль/кГ $-\mathrm{S}$ (small). Через 15 и 30 дней после внутривенного введения КТ у животных регистрировали гематологические показатели, динамику массы тела, а также вели учет погибших животных.

\section{Гематологические исследования}

Гематологические исследования проводили на гематологическом анализаторе URIT-3000 Vet Plus (URIT Medical Electronic; China). Для оценки воздействия KT на организм обращали внимание на следующие гематологические показатели: эритроциты (RBC), средний объем эритроцитов (MCV), лейкоциты (WBC), гемоглобин (HBG), среднее содержание гемоглобина в эритроцитах (MCHC), средний объем эритроцита (МCH), средний объем тромбоцитов (MPV), гематокрит (HCT), абсолютное содержание тромбоцитов (PLT).

\section{Статистический анализ}

Методами дисперсионного анализа для повторных измерений была проведена проверка гипотезы о равенстве средневыборочных величин в нескольких зависимых выборках, значения динамики массы и гематологических показателей в группах - методами непараметрической статистики с указанием медианы, 25-го и 75-го процентилей (Ме (25\%-75\%)). Проверку гипотезы о равенстве средневыборочных величин в независимых выборках проводили с использованием критерия Манна-Уитни. Статистически значимыми считали различия при уровне значимости $p<0,05$. Вычисления

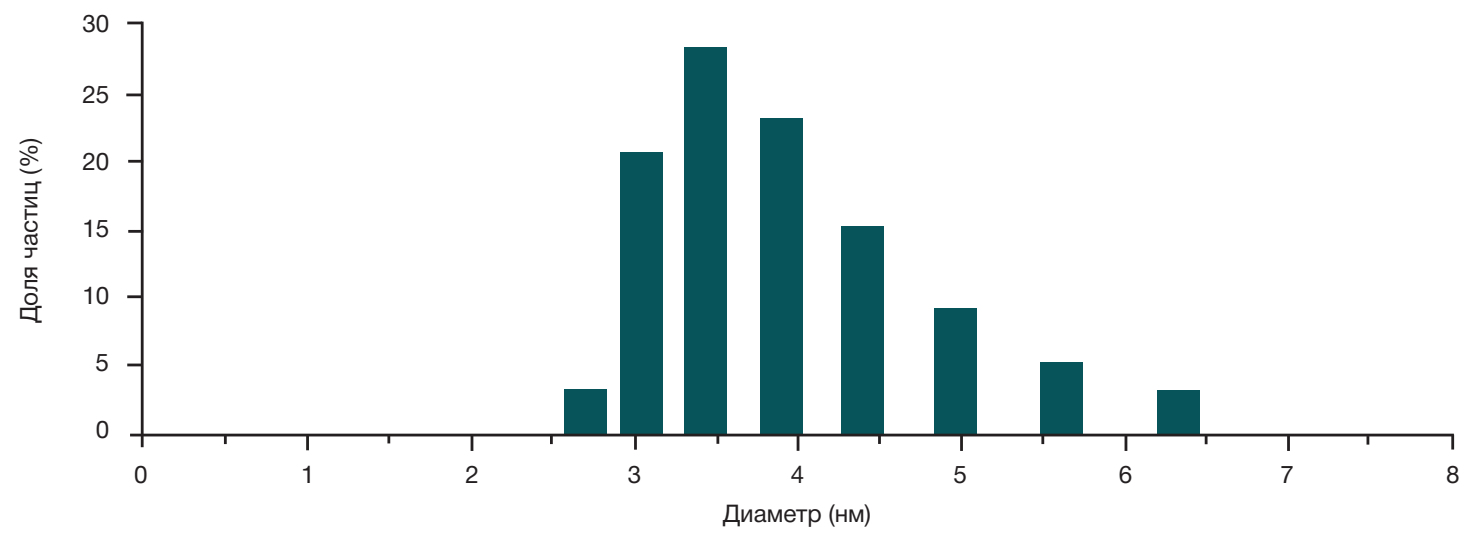

Рис. 1. Гистограмма распределения диаметров $\mathrm{KT}$ AglnS 2 /ZnS при исследовании методом динамического светорассеяния

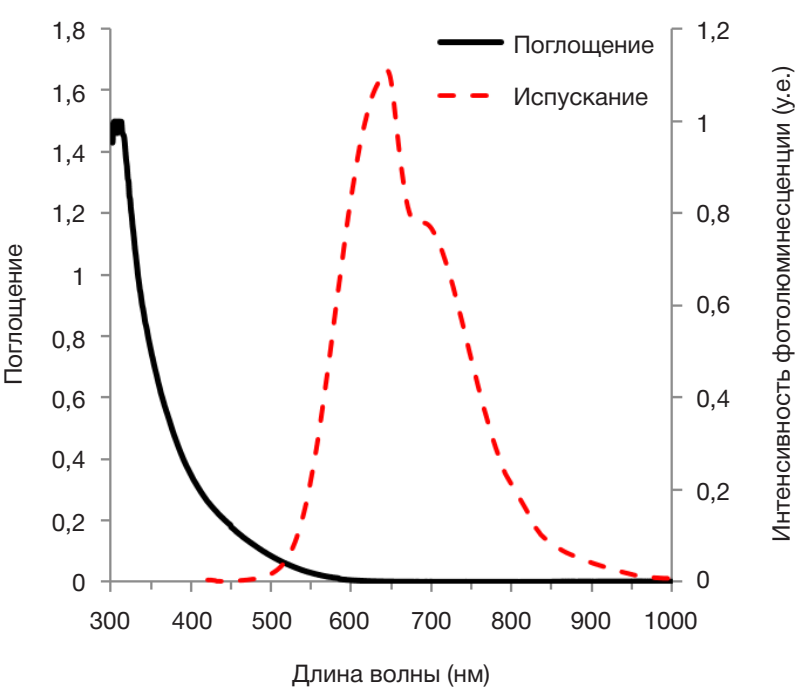

Рис. 2. Спектры поглощения и фотолюминесценции нанокристаллов $A g l n S_{2} / Z n S$ в дистиллированной воде 
производили в программе GraphPad Prism 7.04 (GraphPad Software Inc; США).

Работа выполнена с применением оборудования ресурсных центров «Оптические и лазерные методы исследования вещества» и «Инновационные технологии композитных наноматериалов» Санкт-Петербургского государственного университета.

\section{РЕЗУЛЬТАТЫ ИССЛЕДОВАНИЯ}

\section{Характеристика KT AglnS, $/ 2 n S$}

Результаты исследования КТ методом динамического светорассеяния показано на рис. 1. Наибольшая доля КТ имела средний радиус от 3,0 до 4,5 нм.

На рис. 2 представлены спектры экстинкции и фотолюминесценции водной дисперсии квантовых точек AglnS/ZnS. Дисперсия KT показала пик эмиссии при 627 нм.

Спектр фотолюминесценции отличают заметная несимметричность и достаточно большое значение полуширины на полувысоте. Вместе с большим стоксовым сдвигом это свидетельствует о механизме фотолюминесценции за счет десектов - внутренних и, возможно, поверхностных [16-19]. В этом случае полуширина спектра может зависеть не только от распределения частиц по размерам, но и от распределения и природы дефектов в нанокристаллах [20]. Спектр поглощения не содержит ярко выраженных точек перегиба или максимумов, что в целом характерно для нанокристаллов тройных халькогенидов металлов [16, 21].

\section{Биораспределение КТ}

C помощью фрлуоресцентного визуализатора IVIS Lumina LT Series III была проведена предварительная оценка

A

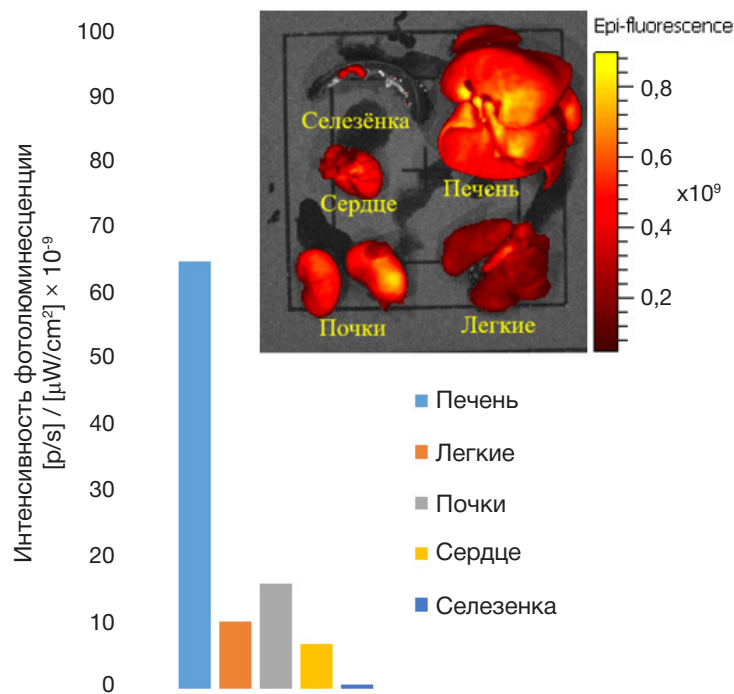

биораспределения КT в органах еx vivo через 1 и 24 ч после внутривенного введения КТ в дозе 4 • 10"6 моль/л (рис. 3).

При исследовании биораспределения КТ на основе AglnS 2 /ZnS было отмечено накопление наночастиц с течением времени в таких органах, как печень, почки, легкие и сердце. Интенсивность флуоресценции печени через 24 ч после введения КТ была значимо выше, чем через 1 чпосле введения, что свидетельствует о накоплении КТ в печени в течение первых суток после введения, тогда как значимых различий уровня флуоресценции в других органах в точках 1 ч и 24 ч отмечено не было.

\section{Масса тела животных}

Динамика массы тела у животных всех опытных групп представлена на рис. 4.

Статистический анализ данных показал отсутствие значимых различий массы тела животных подопытных групп в сравнении с контролем в течение всего эксперимента $(p>0,05)$.

\section{Гематологическое исследование}

Основные гематологические параметры, измеренные на 15-й и 30-й день после введения КТ, представлены на рис. 5.

Изменения гематологических показателей подопытных групп не показали достоверной разницы в сравнении с контрольной группой $(p>0,05)$.

\section{ОБСУЖДДЕНИЕ РЕЗУЛЬТАТОВ}

КТ представляют собой отличную альтернативу традиционным органическим фрлуорофорам, поскольку их размер, химические характеристики поверхности,

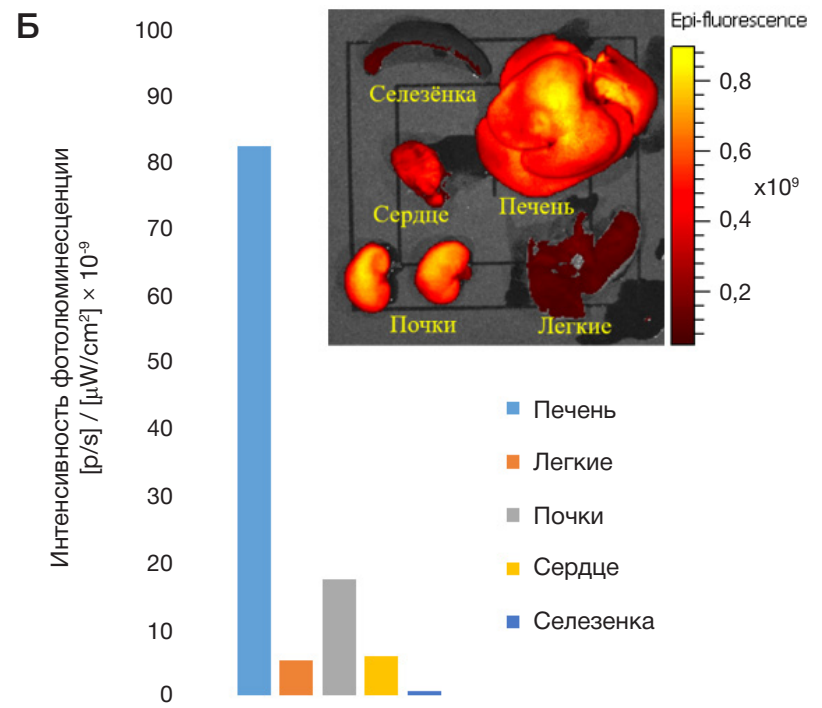

Рис. 3. Визуализация интенсивности флуоресцентного излучения в органах крысы через 1 ч (А) и через 24 ч (Б) после введения KT AglnS 2 /ZnS

A

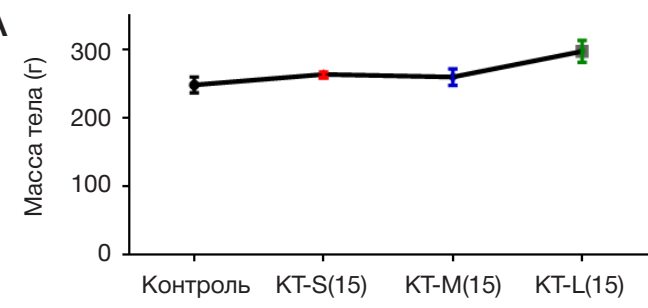

Б

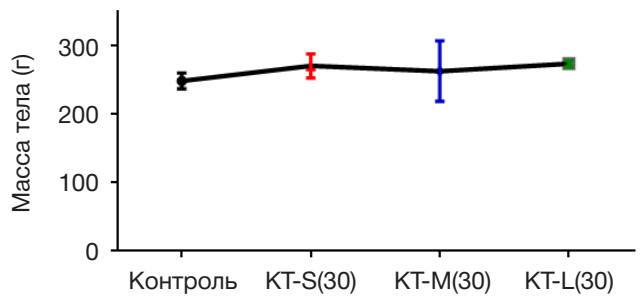

Рис. 4. Динамика массы тела животных 
A

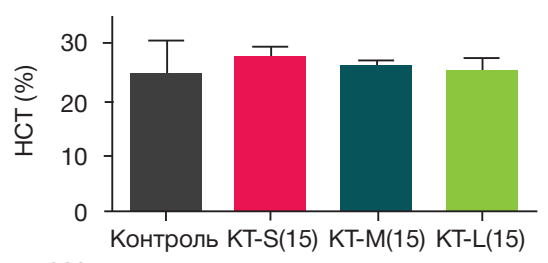

Б

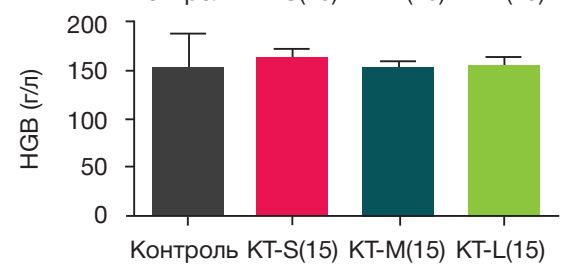

B

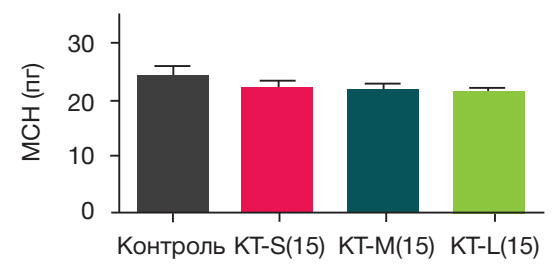

$\Gamma$

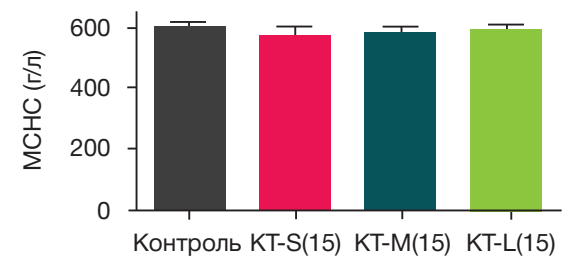

Д

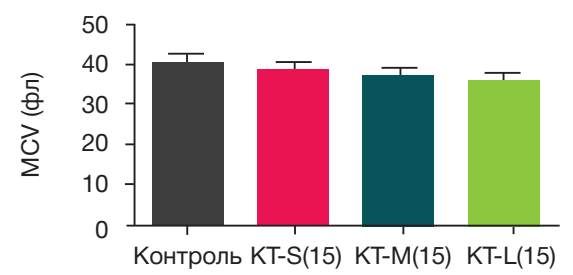

$\mathrm{E}$

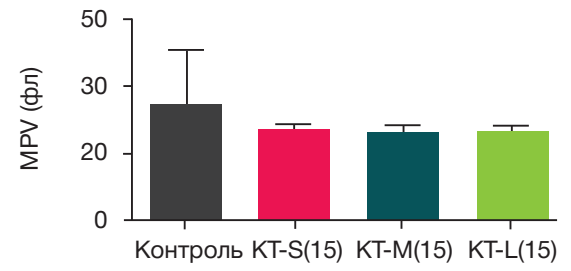

Ж

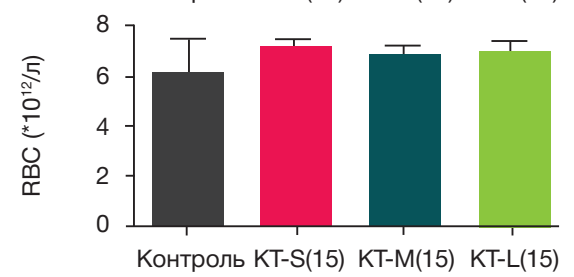

3

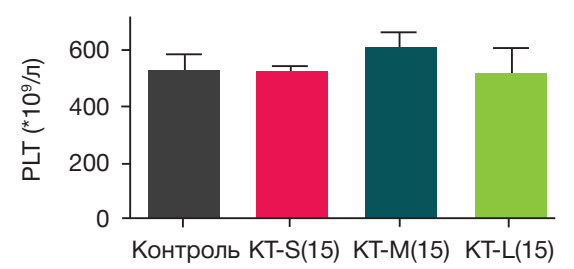

и

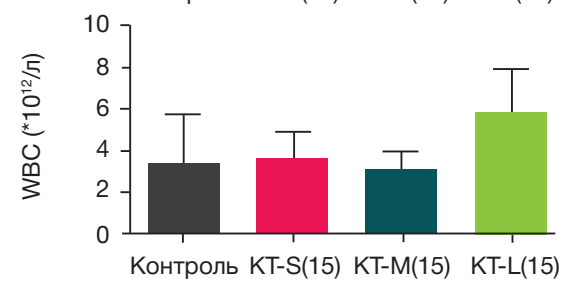

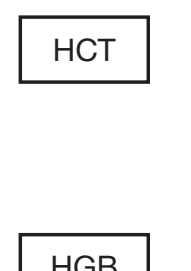

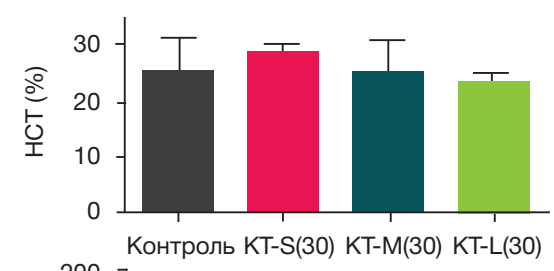

HGB

$\mathrm{MCH}$
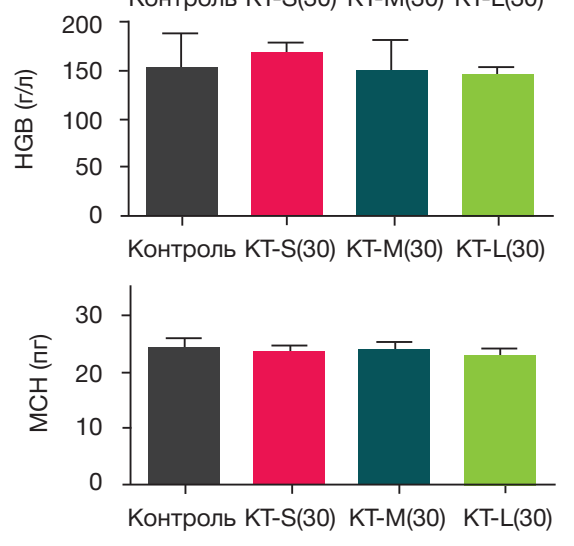

$\mathrm{MCHC}$
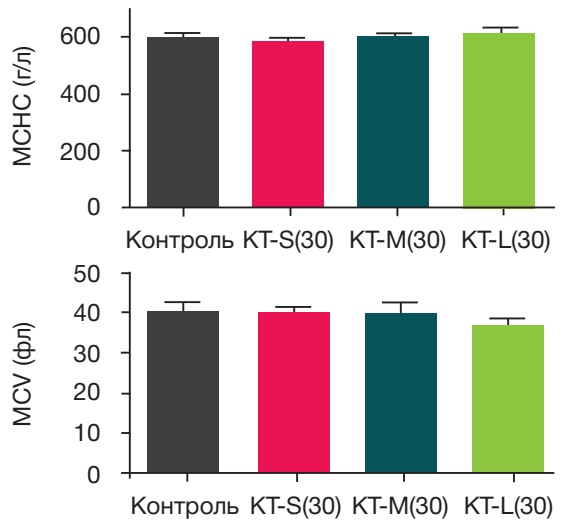

MPV

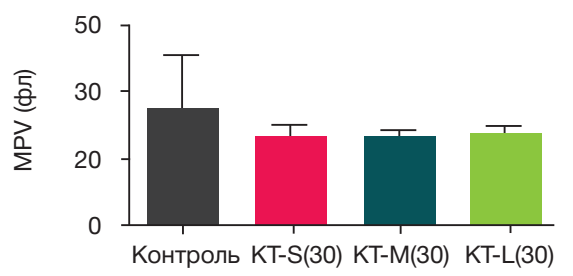

RBC

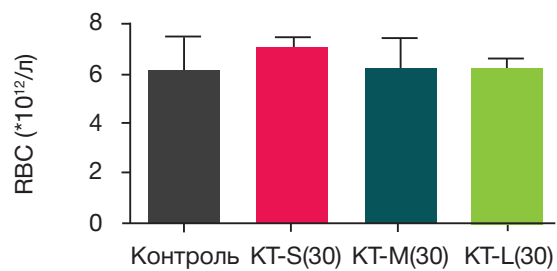

PLT

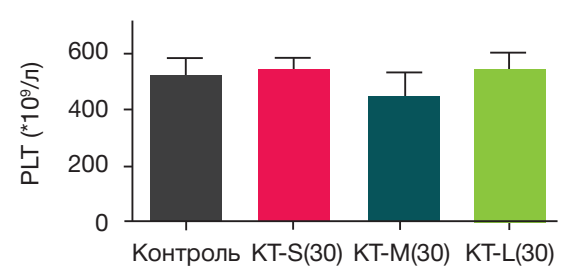

WBC

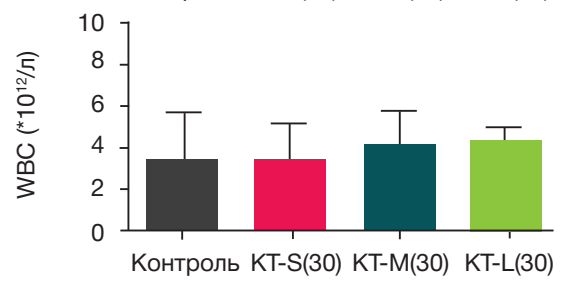

Рис. 5. Результаты исследования гематологических показателей в контроле и через 15 и 30 дней после внутривенного введения КТ в различных дозах 
спектральные свойства и стабильность могут быть легко настроены для оптимизации визуализации in vivo/in vitro. На данный момент в биомедицине КТ разрабатывают и применяют для различных целей, таких как доставка лекарств, диагностические процедуры, визуализация опухолей [21-30]. Следует отметить, что проблемы биораспределения квантовых точек в настоящее время широко исследуют: по данным ряда авторов, их применение в качестве маркеров клеток для визуализации опухолей разных тканей имеет положительные результаты [31-36]. Основными органами-мишенями, в которых происходит накопление квантовых точек, являются печень, почки и селезенка [37-39], легкие [40], кожа, желудочно-кишечный тракт и мочевой пузырь [41], помимо этого, квантовые точки обнаруживаются В лимфатических узлах [42]. В настоящей работе синтезированные инжекционным методом в водной среде коллоидные КТ были использованы для еx vivo визуализации биологического распределения. Полученные нами данные позволяют предположить, что КТ на основе AglnS, ZnS обладают существенной тропностью $\mathrm{k}$ печени, о чем свидетельствует повышение интенсивности флуоресценции с 1 до 24 ч после внутривенного введения. КТ в диапазоне доз от $2 \cdot 10^{-7}$ до $4 \cdot 10^{-6}$ моль/л не обладали системной токсичностью, что подтверждается отсутствием существенных изменений в динамике массы тела и достоверных различий по гематологическим показателям, а также отсутствием гибели животных в течение 30 дней после введения. Учитывая тот момент, что в большинстве случаев экспериментальные образцы KT на основе Cd/Se-ZnS [43] обладают выраженной системной токсичностью, что сказывается, в частности, на гематологических показателях [44], можно предположить, что KT Aglns, $/ \mathrm{ZnS}$ после дополнительного тестирования на животных могут быть применены в качестве флоурофоров в медицинской практике, а возможность иммобилизации на их поверхности лекарственных средств позволит использовать их для тераностики.

\section{ВЫВОДЫ}

Коллоидные KT Aglns, $/ \mathrm{ZnS}$, полученные инжекционным методом в водной среде, при исследовании биолюминесценции, проявили себя как стабильные структуры, которые могут быть использованы в продолжительных исследованиях. Оценка биораспределения КТ показала, что они имеют свойство накапливаться в таких органах, как печень, легкие, сердце и почки. Исследование биологической совместимости КТ показало, что в диапазоне доз от $2 \cdot 10^{-7}$ до $4 \cdot 10^{-6}$ моль/л при внутривенном введении крысам КТ не оказывают значимого влияния на динамику массы тела и основные гематологические показатели на протяжении 30 дней.

\section{Литература}

1. Мелерзанов А., Москалев А., Жаров В. Прецизионная медицина и молекулярная тераностика. Врач. 2016; (12): 11-14.

2. Гареев К. Г., Бабикова К. Ю., Наумышева Е. Б., Постнов В. Н., Королев Д. В. Синтез наноматериалов с флуоресцентной меткой для медицинского назначения. Биотехносфера. 2017; 3 (51): 61-8.

3. Kobayashi H, Ogawa M, Alford R, Choyke PL, Urano Y. New Strategies for Fluorescent Probe Design in Medical Diagnostic Imaging. Chem Rev. 2010; 110 (5): 2620-40.

4. Истомина М. С., Королев Д. В., Почкаева Е. И., Мазинг Д. С., Мошников В. А., Гареев К. Г., Бабикова К. Ю., Постнов В. Н. исследование возможности использования коллоидных квантовых точек на основе AglnS2/ZnS для флуоресцентного имиджинга в сравнении с флуорофорами, закрепленными на поверхности наночастиц. Трансляционная медицина. 2017; 4 (4): 56-65.

5. Oh E, Liu R, Nel A, Gemill KB, Bilal M, Cohen Y, Medintz IL. Metaanalysis of cellular toxicity for cadmium-containing quantum dots. Nature nanotechnology. 2016; (11): 479-86.

6. Tsoi KM, Dai Q, Alman BA, Chan WCW. Are quantum dots toxic? Exploring the discrepancy between cell culture and animal studies. Acc Chem Res. 2013; (46): 662-71.

7. Ye $L$, Yong $K T$, Liu $L$ et al. A pilot study in non-human primates shows no adverse response to intravenous injection of quantum dots. Nature Nanotech. 2012; (7): 453-8.

8. Winnik FM, Maysinger D. Quantum dot cytotoxicity and ways to reduce it. Acc Chem Res. 2013; (46): 672-80.

9. Ding $\mathrm{Ya}$ et al. Gold nanoparticles for nucleic acid delivery. Molecular therapy. 2014; 22 (6): 1075-83.

10. Fitzpatrick JA. Andreko SK, Ernst LA, Waggoner AS, Ballou B, Bruchez MP. Long-term persistence and spectral blue shifting of quantum dots in vivo. Nano Lett. 2009; (9): 2736-41.

11. Nel AE, Mädler L, Velegol D, Xia T, Hoek EM, Somasundaran P et al. Understanding biophysicochemical interactions at the nanobio interface. Nature Mater. 2009; 8 (7): 543-57.

12. Li MM, Cao J, Yang JC, Shen YJ, Cai XL, Chen YW et al. Biodistribution and toxicity assessment of intratumorally injected arginine-glycine-aspartic acid peptide conjugated to CdSe/ZnS

quantum dots in mice bearing pancreatic neoplasm. Chem Biol Interact. 2018; (291): 103-10.

13. Dine EJ, Marchal S, Schneider R, Hamie B, Ghanbaja J, RoquesCarmes $T$ et al. A facile approach for doxorubicine delivery in cancer cells by responsive and fluorescent core/shell quantum dots. Bioconjug Chem. 2018; 29 (7): 2248-56.

14. Лесничая М. В., Сухов Б. Г., Шендрик Р. Ю., Сапожников А. Н., Трофимов Б. А. Синтез водорастворимых квантовых точек селенида серебра, люминесцирующих в окне прозрачности биологических тканей. Журнал общей химии. 2018; 88 (2): 307-10.

15. Huang $Y$, Gao Y, Zhang Q, Zhang Y, Cao JJ, Ho W et al. Biocompatible $\mathrm{FeOOH}-\mathrm{Carbon}$ quantum dots nanocomposites for gaseous NOx removal under visible light: Improved charge separation and High selectivity. J Hazard Mater. 2018; (354): 54-62.

16. Drobintseva A, Polyakova V, Matyushkin L, Krylova Y, Masing D, Aleksandrova $\mathrm{OA}$ et al. Characterization of ZnSe/ZnS QD Conjugated with Antibody Labeling Kisspeptins. In 3-rd Int. Conf. of BioPhotonics, Florence, Italy. 2015.

17. Alivisatos AP, Gu W, Larabell C. Quantum dots as cellular probes. Annu Rev Biomed Eng. 2005; (7): 55-76.

18. Somers RC, Bawendi MG, Nocera DG. CdSe nanocrystal based chem-/bio-sensors. Chemical Society Reviews. 2007; 36 (4): 579-91.

19. Shamirian A, Appelbe O, Zhang Q, Ganesh B, Kron SJ, Snee PT. A toolkit for bioimaging using near-infrared AglnS2/ZnS quantum dots. Journal of Materials Chemistry B. 2015; 3 (41): 8188-96.

20. Bruchez M, Moronne M, Gin P, Weiss S, Alivisatos AP. Semiconductor nanocrystals as fluorescent biological labels. Science. 1998; 281 (5385): 2013-6.

21. Chan WCW, Nie S. Quantum dot bioconjugates for ultrasensitive nonisotopic detection. Science. 1998; 281 (5385): 2016-8.

22. Tyrakowski CM, Snee PT. A primer on the synthesis, watersolubilization, and functionalization of quantum dots, their use as biological sensing agents, and present status Physical Chemistry Chemical Physics. 2014; 16 (3): 837-55.

23. Yaghini E, Turner HD, Le Marois AM, Suhling K, Naasani I, MacRobert AJ. In vivo biodistribution studies and ex vivo lymph 
node imaging using heavy metal-free quantum dots. Biomaterials. 2016; (104): 182-91.

24. Matea CT, Mocan T, Tabaran F, et al. Quantum dots in imaging, drug delivery and sensor applications. International Journal of Nanomedicine. 2017; (12): 5421-31.

25. Wang L-W, Peng C-W, Chen C, Li Y. Quantum dots-based tissue and in vivo imaging in breast cancer researches: current status and future perspectives. Breast Cancer Research and Treatment. 2015; 151 (1): 7-17.

26. Wegner KD, Hildebrandt N. Quantum dots: bright and versatile in vitro and in vivo fluorescence imaging biosensors. Chemical Society Reviews. 2015; 44 (14): 4792-834.

27. Walling MA, Novak JA, Shepard JRE. Quantum Dots for live cell and in vivo imaging. International Journal of Molecular Sciences. 2009; 10 (2): 441-91.

28. Kang Yan-Fei et al. Carbon quantum dots for zebrafish fluorescence imaging. Scientific reports. 2005; (5): 11835

29. Xu G, Lin G, Lin S, Wu N, Deng Y, Feng G et al. The Reproductive Toxicity of CdSe/ZnS Quantum Dots on the in vivo Ovarian Function and in vitro Fertilization. Scientific reports. 2016; (6): 37677.

30. Tang H, Yang ST, Yang YF, Ke DM, Liu JH, Chen X et al. Blood clearance, distribution, transformation, excretion, and toxicity of near-infrared quantum dots Ag2Se in mice. ACS applied materials \& interfaces. 2018; 8 (28): 17859-69.

31. Wang C, Gao X, Su X. In vitro and in vivo imaging with quantum dots. Analytical and bioanalytical chemistry. 2010; 397 (4): $1397-$ 415.

32. Gao J, Chen K, Xie R et al. In Vivo Tumor-targeted fluorescence imaging using near-infrared non-cadmium quantum dots. Bioconjugate chemistry. 2010; 21 (4): 604-9.

33. Liu X, Zhou P, Zhan H, Liu H, Zhang J et al. Synthesis and characterization of near-infrared-emitting $\mathrm{CdHgTe/CdS/ZnS}$ quantum dots capped by $\mathrm{N}$-acetyl-L-cysteine for in vitro and in vivo imaging. RSC Advances. 2017; 7 (48): 29998-30007.

\section{References}

1. Melerzanov A, Moskalev A, Zharov V. Precizionnaja medicina molekuljarnaja teranostika. Vrach. 2016; (12): 11-14.

2. Gareev KG, Babikova KJu, Naumysheva EB, Postnov VN, Korolev DV. Sintez nanomaterialov s fluorescentnoj metkoj dlja medicinskogo naznachenija. Biotehnosfera. 2017; 3 (51): 61-8.

3. Kobayashi H, Ogawa M, Alford R, Choyke PL, Urano Y. New Strategies for Fluorescent Probe Design in Medical Diagnostic Imaging. Chem Rev. 2010; 110 (5): 2620-40.

4. Istomina MS, Korolev DV, Pochkaeva El, Mazing DS, Moshnikov VA Gareev KG, Babikova KJu, Postnov VN. issledovanie vozmozhnost ispol'zovanija kolloidnyh kvantovyh tochek na osnove AglnS2/ ZnS dlja fluorescentnogo imidzhinga $v$ sravnenii $s$ fluoroforami, zakreplennymi na poverhnosti nanochastic. Transljacionnaja medicina. 2017; 4 (4): 56-65.

5. Oh E, Liu R, Nel A, Gemill KB, Bilal M, Cohen Y, Medintz IL. Metaanalysis of cellular toxicity for cadmium-containing quantum dots. Nature nanotechnology. 2016; (11): 479-86.

6. Tsoi KM, Dai Q, Alman BA, Chan WCW. Are quantum dots toxic? Exploring the discrepancy between cell culture and animal studies. Acc Chem Res. 2013; (46): 662-71.

7. Ye L, Yong KT, Liu L et al. A pilot study in non-human primates shows no adverse response to intravenous injection of quantum dots. Nature Nanotech. 2012; (7): 453-8.

8. Winnik FM, Maysinger D. Quantum dot cytotoxicity and ways to reduce it. Acc Chem Res. 2013; (46): 672-80.

9. Ding Ya et al. Gold nanoparticles for nucleic acid delivery. Molecular therapy. 2014; 22 (6): 1075-83.

10. Fitzpatrick JA. Andreko SK, Ernst LA, Waggoner AS, Ballou B, Bruchez MP. Long-term persistence and spectral blue shifting of quantum dots in vivo. Nano Lett. 2009; (9): 2736-41.

11. Nel AE, Mädler L, Velegol D, Xia T, Hoek EM, Somasundaran P et al. Understanding biophysicochemical interactions at the nanobio interface. Nature Mater. 2009; 8 (7): 543-57.
34. Lin $G$ et al. Passive tumor targeting and imaging by using mercaptosuccinic acid-coated near-infrared quantum dots. International journal of nanomedicine. 2015; (10): 335

35. Singh SK et al. Drug delivery approaches for breast cancer. International journal of nanomedicine. 2017; (12): 6205.

36. Han X, Wang Y, Shi D. Preparation of QDs@ SiO2/polystyrene composite particles for cancer cells detection. Nano LIFE. 2018.

37. Jain $S$ et al. Applications of Fluorescent Quantum Dots for Reproductive Medicine and Disease Detection. In: Park SB, editor. Rijeka: IntechOpen, 2018; 6.

38. Schipper ML, lyer G, Koh AL, Cheng Z, Ebenstein Y, Aharoni A et al. Particle size, surface coating, and PEGylation influence the biodistribution of quantum dots in living mice. Small. 2009; 5 (1): 126-34.

39. Yang L, Kuang $\mathrm{H}$, Zhang W, Wei H, Xu H. Quantum dots cause acute systemic toxicity in lactating rats and growth restriction of offspring. Nanoscale. 2018; 10 (24): 11564-77.

40. Roberts JR, Antonini JM, Porter DW et al. Lung toxicity and biodistribution of $\mathrm{Cd} / \mathrm{Se}$-ZnS quantum dots with different surface functional groups after pulmonary exposure in rats. Particle and Fibre Toxicology. 2013; (10): 5.

41. Park $Y$, Ryu $Y M$, Jung $Y$ et al. Spraying quantum dot conjugates in the colon of live animals enabled rapid and multiplex cancer diagnosis using endoscopy. ACS nano. 2014; 8 (9): 8896-910.

42. Salykina YF, Zherdeva W, Dezhurov SV et al. Biodistribution and clearance of quantum dots in small animals. Saratov Fall Meeting 2010: Optical Technologies in Biophysics and Medicine. 2011; (12): 7999.

43. Roberts JR, Antonini JM, Porter DW et al. Lung toxicity and biodistribution of $\mathrm{Cd} / \mathrm{Se}$-ZnS quantum dots with different surface functional groups after pulmonary exposure in rats. Particle and Fibre Toxicology. 2013; 10 (5).

44. Park Y, Ryu YM, Jung $Y$ et al. Spraying quantum dot conjugates in the colon of live animals enabled rapid and multiplex cancer diagnosis using endoscopy. ACS Nano. 2014; 7 (1): 9309.

12. Li MM, Cao J, Yang JC, Shen YJ, Cai XL, Chen YW et al. Biodistribution and toxicity assessment of intratumorally injected arginine-glycine-aspartic acid peptide conjugated to CdSe/ZnS quantum dots in mice bearing pancreatic neoplasm. Chem Biol Interact. 2018; (291): 103-10.

13. Dine EJ, Marchal S, Schneider R, Hamie B, Ghanbaja J, RoquesCarmes $T$ et al. A facile approach for doxorubicine delivery in cancer cells by responsive and fluorescent core/shell quantum dots. Bioconjug Chem. 2018; 29 (7): 2248-56.

14. Lesnichaja MV, Suhov BG, Shendrik RJu, Sapozhnikov AN, Trofimov BA. Sintez vodorastvorimyh kvantovyh tochek selenida serebra, ljuminescirujushhih $v$ okne prozrachnosti biologicheskih tkanej. Zhurnal obshhej himii. 2018; 88 (2): 307-10.

15. Huang $Y$, Gao $Y$, Zhang $Q$, Zhang $Y$, Cao JJ, Ho $W$ et al. Biocompatible $\mathrm{FeOOH}$-Carbon quantum dots nanocomposites for gaseous NOx removal under visible light: Improved charge separation and High selectivity. J Hazard Mater. 2018; (354): 54-62.

16. Drobintseva A, Polyakova V, Matyushkin L, Krylova Y, Masing D, Aleksandrova $\mathrm{OA}$ et al. Characterization of ZnSe/ZnS QD Conjugated with Antibody Labeling Kisspeptins. In 3-rd Int. Conf. of BioPhotonics, Florence, Italy. 2015.

17. Alivisatos AP, Gu W, Larabell C. Quantum dots as cellular probes. Annu Rev Biomed Eng. 2005; (7): 55-76.

18. Somers RC, Bawendi MG, Nocera DG. CdSe nanocrystal based chem-/bio-sensors. Chemical Society Reviews. 2007; 36 (4): 579-91.

19. Shamirian A, Appelbe O, Zhang Q, Ganesh B, Kron SJ, Snee PT. A toolkit for bioimaging using near-infrared AglnS2/ZnS quantum dots. Journal of Materials Chemistry B. 2015; 3 (41): 8188-96.

20. Bruchez M, Moronne M, Gin P, Weiss S, Alivisatos AP. Semiconductor nanocrystals as fluorescent biological labels. Science. 1998; 281 (5385): 2013-6.

21. Chan WCW, Nie S. Quantum dot bioconjugates for ultrasensitive nonisotopic detection. Science. 1998; 281 (5385): 2016-8. 
22. Tyrakowski CM, Snee PT. A primer on the synthesis, watersolubilization, and functionalization of quantum dots, their use as biological sensing agents, and present status Physical Chemistry Chemical Physics. 2014; 16 (3): 837-55.

23. Yaghini E, Turner HD, Le Marois AM, Suhling K, Naasani I, MacRobert AJ. In vivo biodistribution studies and ex vivo lymph node imaging using heavy metal-free quantum dots. Biomaterials. 2016; (104): 182-91.

24. Matea CT, Mocan T, Tabaran F, et al. Quantum dots in imaging, drug delivery and sensor applications. International Journal of Nanomedicine. 2017; (12): 5421-31.

25. Wang L-W, Peng C-W, Chen C, Li Y. Quantum dots-based tissue and in vivo imaging in breast cancer researches: current status and future perspectives. Breast Cancer Research and Treatment. 2015; 151 (1): 7-17.

26. Wegner KD, Hildebrandt N. Quantum dots: bright and versatile in vitro and in vivo fluorescence imaging biosensors. Chemical Society Reviews. 2015; 44 (14): 4792-834.

27. Walling MA, Novak JA, Shepard JRE. Quantum Dots for live cel and in vivo imaging. International Journal of Molecular Sciences. 2009; 10 (2): 441-91.

28. Kang Yan-Fei et al. Carbon quantum dots for zebrafish fluorescence imaging. Scientific reports. 2005; (5): 11835.

29. Xu G, Lin G, Lin S, Wu N, Deng Y, Feng G et al. The Reproductive Toxicity of CdSe/ZnS Quantum Dots on the in vivo Ovarian Function and in vitro Fertilization. Scientific reports. 2016; (6): 37677.

30. Tang H, Yang ST, Yang YF, Ke DM, Liu JH, Chen X et al. Blood clearance, distribution, transformation, excretion, and toxicity of near-infrared quantum dots Ag2Se in mice. ACS applied materials \& interfaces. 2018; 8 (28): 17859-69.

31. Wang C, Gao X, Su X. In vitro and in vivo imaging with quantum dots. Analytical and bioanalytical chemistry. 2010; 397 (4): 1397-415.

32. Gao J, Chen K, Xie R et al. In Vivo Tumor-targeted fluorescence imaging using near-infrared non-cadmium quantum dots. Bioconjugate chemistry. 2010; 21 (4): 604-9.

33. Liu X, Zhou P, Zhan H, Liu H, Zhang J et al. Synthesis and characterization of near-infrared-emitting CdHgTe/CdS/ZnS quantum dots capped by $\mathrm{N}$-acetyl-L-cysteine for in vitro and in vivo imaging. RSC Advances. 2017; 7 (48): 29998-30007.

34. Lin $G$ et al. Passive tumor targeting and imaging by using mercaptosuccinic acid-coated near-infrared quantum dots. International journal of nanomedicine. 2015; (10): 335

35. Singh SK et al. Drug delivery approaches for breast cancer International journal of nanomedicine. 2017; (12): 6205.

36. Han X, Wang Y, Shi D. Preparation of QDs@ SiO2/polystyrene composite particles for cancer cells detection. Nano LIFE. 2018.

37. Jain $S$ et al. Applications of Fluorescent Quantum Dots for Reproductive Medicine and Disease Detection. In: Park SB, editor. Rijeka: IntechOpen, 2018; 6 .

38. Schipper ML, Iyer G, Koh AL, Cheng Z, Ebenstein Y, Aharoni A et al. Particle size, surface coating, and PEGylation influence the biodistribution of quantum dots in living mice. Small. 2009; 5 (1): 126-34.

39. Yang $L$, Kuang $H$, Zhang $W$, Wei $H, X u H$. Quantum dots cause acute systemic toxicity in lactating rats and growth restriction of offspring. Nanoscale. 2018; 10 (24): 11564-77.

40. Roberts JR, Antonini JM, Porter DW et al. Lung toxicity and biodistribution of $\mathrm{Cd} / \mathrm{Se}-\mathrm{ZnS}$ quantum dots with different surface functional groups after pulmonary exposure in rats. Particle and Fibre Toxicology. 2013; (10): 5.

41. Park Y, Ryu YM, Jung $Y$ et al. Spraying quantum dot conjugates in the colon of live animals enabled rapid and multiplex cancer diagnosis using endoscopy. ACS nano. 2014; 8 (9): 8896-910.

42. Salykina YF, Zherdeva W, Dezhurov SV et al. Biodistribution and clearance of quantum dots in small animals. Saratov Fall Meeting 2010: Optical Technologies in Biophysics and Medicine. 2011; (12): 7999.

43. Roberts JR, Antonini JM, Porter DW et al. Lung toxicity and biodistribution of $\mathrm{Cd} / \mathrm{Se}-\mathrm{ZnS}$ quantum dots with different surface functional groups after pulmonary exposure in rats. Particle and Fibre Toxicology. 2013; 10 (5).

44. Park Y, Ryu YM, Jung $Y$ et al. Spraying quantum dot conjugates in the colon of live animals enabled rapid and multiplex cancer diagnosis using endoscopy. ACS Nano. 2014; 7 (1): 9309. 